\title{
Phospholipid analysis in sera of horses with allergic dermatitis and in matched healthy controls
}

Raija Hallamaa ${ }^{1,2^{*}}$ and Krishna Batchu ${ }^{3}$

\begin{abstract}
Background: Lipids have become an important target for searching new biomarkers typical of different autoimmune and allergic diseases. The most common allergic dermatitis of the horse is related to stings of insects and is known as insect bite hypersensitivity (IBH) or summer eczema, referring to its recurrence during the summer months. This intense pruritus has certain similarities with atopic dermatitis of humans. The treatment of IBH is difficult and therefore new strategies for therapy are needed. Autoserum therapy based on the use of serum phospholipids has recently been introduced for horses. So far, serum lipids relating to these allergic disorders have been poorly determined. The main aim of this study was to analyse phospholipid profiles in the sera of horses with allergic dermatitis and in their healthy controls and to further assess whether these lipid profiles change according to the clinical status after therapy.

Methods: Sera were collected from 10 horses with allergic dermatitis and from 10 matched healthy controls both before and 4 weeks after the therapy of the affected horses. Eczema horses were treated with an autogenous preparation made from a horse's own serum and used for oral medication. Samples were analysed for their phospholipid content by liquid chromatography coupled to a triple-quadrupole mass spectrometer (LC-MS). Data of phospholipid concentrations between the groups and over the time were analysed by using the Friedman test. Correlations between the change of concentrations and the clinical status were assessed by Spearman's rank correlation test.

Results: The major phospholipid classes detected were phosphatidylcholine (PC), sphingomyelin (SM), phosphatidylinositol (PI) and phosphatidylethanolamine (PE). Eczema horses had significantly lower total concentrations of PC $(p<0.0001)$ and SM $(p=0.0115)$ than their healthy controls. After a 4-week therapy, no significant differences were found between the groups. Changes in SM concentrations correlated significantly with alterations in clinical signs $(p=0.0047)$.
\end{abstract}

Conclusions: Horses with allergic dermatitis have an altered phospholipid profile in their sera as compared with healthy horses and these profiles seem to change according to their clinical status. Sphingomyelin seems to have an active role in the course of equine insect bite hypersensitivity.

Keywords: Horse, Allergy, Allergic dermatitis, Lipids, Phospholipids, Insect bite hypersensitivity, Summer eczema, Autoserum therapy

\footnotetext{
* Correspondence: raija.hallamaa@elisanet.fi

${ }^{1}$ Veterinary Clinic, Nummela, Finland

${ }^{2}$ University of Helsinki, Faculty of Veterinary Medicine, Helsinki, Finland

Full list of author information is available at the end of the article
} 


\section{Background}

Various new and important insights into the roles of lipids have been demonstrated over the past few decades. Most of these findings are related to inflammatory and immune responses including studies on pro-resolving lipid mediators [1, 2], lipid antigens [3, 4] and lipid presenting CD1 molecules [5-7]. Mass spectrometry with specific software applications has made it possible to identify and quantify a multitude of lipid species both in mammalian cells and also of those existing in circulation [8-12]. Although phospholipids are commonly present in mammalian sera $[13,14]$, changes in their concentrations under various pathological conditions are so far poorly understood $[9,15,16]$. Presently, there is an increasing need to find new biomarkers feasible for diagnosis, treatment and prognosis - not only in allergic diseases, but also in other immune mediated and neurological disorders [2, 16-23].

Insect bite hypersensitivity (Fig. 1a) is the most common allergic skin disease of the horse [24] displaying many features similar to atopic dermatitis (AD) of humans $[25,26]$. Intense and recurrent pruritus, IgEmediated responses, perivascular mast cell, eosinophil and T-lymphocyte infiltrations are typical findings of both disorders [25, 27-32]. In addition, horses with insect hypersensitivity show IgE-mediated sensitization also to various environmental allergens [27], as do patients with atopic dermatitis [31, 32]. However, disturbed skin barrier function due to inherited defects of filaggrin has not been studied on horses [26]. Treatment of equine IBH is challenging, since total isolation from biting insects is impossible. Antihistamines or allergen-specific immunotherapy have not been beneficial $[33,34]$. Therefore there is a need for comprehensive understanding of this harmful disease. In our previous study [35], we analysed phospholipid contents of autoserum preparations that have been recently used in the therapy of insect hypersensitivity in horses. The idea is to collect remnant lipid particles in these preparations after serial washings [35]. Concentrations of phosphatidylcholine (PC) and sphingomyelin (SM) were significantly more abundant in the preparations made from the sera of the affected than from healthy horses and the amounts of these phospholipids showed significant associations with the severity of prevailing clinical status [35].

The purpose of the current study was to analyse by liquid chromatography-mass spectrometry (LC-MS) phospholipids in the sera of horses with insect bite allergic dermatitis and in their matched healthy controls. We hypothesize that phospholipid profiles may differ between the groups. The additional aim was to assess whether these profiles change according to the clinical status after autoserum therapy.

\section{Results}

The main phospholipid classes analysed were phosphatidylcholine (PC), phosphatidylethanolamine (PE), phosphatidylserine (PS), phosphatidylinositol (PI), phosphatidic acid (PA) and sphingomyelin (SM). Of these, all except for PS were detected across all the samples. Relative contents of the major phospholipid classes before (stage 0) and after the 4-week therapy (stage 4) of eczema horses are listed in Table 1. In addition to the major phospholipid classes, all the samples also contained PA 36:2 and lysoPC species of 16:0, 18:2 and 18:0.

Phosphatidylcholine was the most abundant of all the phospholipid classes detected (Table 1). Its major molecular species in both eczema and control horses at stages 0 and 4 are presented in Figs. 2 and 3, respectively. Of the molecular species, PC $36: 2$ was the most abundant. Additionally, trace amounts of PC 26:0, 28:0, $31: 1,33: 1,33: 2,33: 3,36: 2,36: 3,36: 6$ and $38: 8$ were detected. In the samples collected later in the summer (Table 2), PC concentrations were found to be more abundant than in the samples taken earlier (Figs. 2 and 3). Horses in the eczema group had a significantly lower total concentration of $\mathrm{PC}$ than healthy horses before the start of the therapy (Table 3). After the 4-week therapy, no significant difference could be found between the groups (Table 3, Fig. 3). In the eczema group, the total PC concentration had increased significantly, while in the control

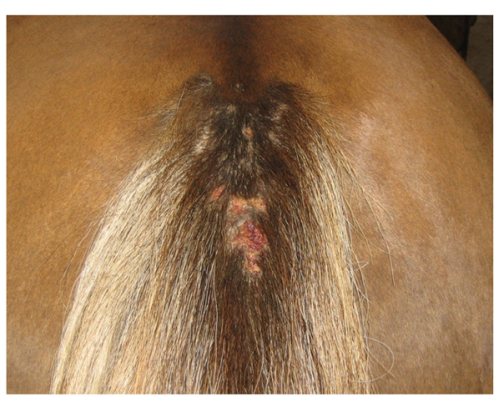

a

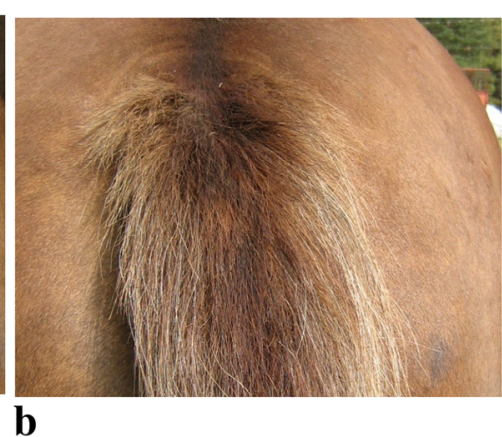

Fig. 1 Typical clinical signs in the tail of a horse with insect bite allergic dermatitis (a) and the same horse after a 4-week therapy (b) 
Table 1 Relative contents of the major phospholipids detected in sera of the horses

\begin{tabular}{lcc}
\hline Phospholipids & \multicolumn{2}{c}{ Relative content (mean \pm sd/\%) } \\
\cline { 2 - 3 } & Eczema group & Control group \\
\hline & Stage 0 & $83.3 \pm 9.8$ \\
PC & $76.0 \pm 4.8$ & $14.8 \pm 8.5$ \\
SM & $21.9 \pm 3.8$ & $1.7 \pm 1.5$ \\
PI & $1.9 \pm 1.4$ & $0.2 \pm 0.2$ \\
PE & $0.2 \pm 0.2$ & \\
& Stage 4 & $85.6 \pm 2.7$ \\
PC & $87.4 \pm 1.7$ & $12.4 \pm 1.9$ \\
SM & $11.0 \pm 1.6$ & $1.8 \pm 1.3$ \\
PI & $1.4 \pm 0.7$ & $0.2 \pm 0.2$ \\
PE & $0.2 \pm 0.2$ &
\end{tabular}

Samples of horses with allergic dermatitis $(n=10)$ and their matched healthy controls $(n=10)$ are collected before treatment (stage 0 ) and when affected horses have been on autoserum therapy for 4 weeks (stage 4). Phospholipid classes: phosphatidylcholine (PC), sphingomyelin (SM), phosphatidylinositol $(\mathrm{PI})$, phosphatidylethanolamine (PE).

group there was a small decrease (Figs. 2 and 3). Concentrations of all the major molecular species presented in Figs. 2 and 3 increased significantly (at level $p<0.05$ ) in the affected horses between stages 0 and 4 , while in the healthy horses, the only significant change observed was a decrease in the concentration of PC 40:8 ( $P=0.0007)$.

Concentrations of SM were found to be significantly lower in eczema horses in comparison with their healthy controls at stage 0 (Table 3 ), although the relative content of SM was higher in the affected horses (Table 1). The total SM concentrations decreased in both groups during the study period (Table 3, Figs. 4 and 5) and at the second sampling there was no significant difference observed between the two groups (Table 3). The major SM species detected and their changes between the stages 0 and 4 are shown in Figs. 4 and 5. The most abundant species was SM 20:0 in both groups and its concentration differed neither between the groups nor the stages. Concentrations of SM 16:0, 18:0, 24:0 and 24:1 decreased significantly (at level $p<0.05$ ) between the stages in both eczema and healthy horses. Concentrations of SM, like PC, were more abundant in the samples collected later in the summer (Table 2, Figs. 4 and 5).

Phosphatidylinositol and PE displayed small amounts of the phospholipids detected (Table 1). Of PI, molecular species of 32:0, 34:1, 34:2, 36:1, 36:2, 36:3, 36:4 and 38:4 were found. The pairwise comparisons showed no significant differences between the two groups at any stages (Table 3). The detected molecular species of PE were that of 32:0, 36:1, 36:2, 36:3, 36:4, 38:4 and 38:5. Unlike PI, the amounts of PE increased significantly from stage 0 to 4 in both groups (Table 3). However, its relative content did not change due to its small total amount (Table 1). No significant differences between the groups were observed at any of the stages.

Five of the horses had mild and 5 moderate clinical signs at the beginning of the study and the total score of signs was 15 , according to the 3 -graded scale used. After a 4-week autoserum therapy, the signs had relieved in 6 horses (Fig. 1b), remained unchanged in 3, while one horse suffered from aggravated clinical signs, the total score being 10. Horses with positive clinical outcome showed a milder decrease in SM concentrations than horses with poorer response or controls (Fig. 6). The change in total SM concentrations correlated significantly with alterations in the clinical signs $(P=0.0047)$ and of the major molecular species, SM 15:0 exhibited a significant correlation $(P=0.0268)$. None of the other phospholipid classes showed significant correlations with the change of clinical signs.

No side effects relating to the therapy were observed. Control horses did not develop signs typical of IBH during the study period.

\section{Discussion}

The purpose of this study was to analyse the major phospholipids typical of mammals in the sera of healthy horses and horses with allergic dermatitis. The additional aim was to assess whether profiles of the detected phospholipids change according to clinical status when horses were treated with an autogenous serum preparation. In
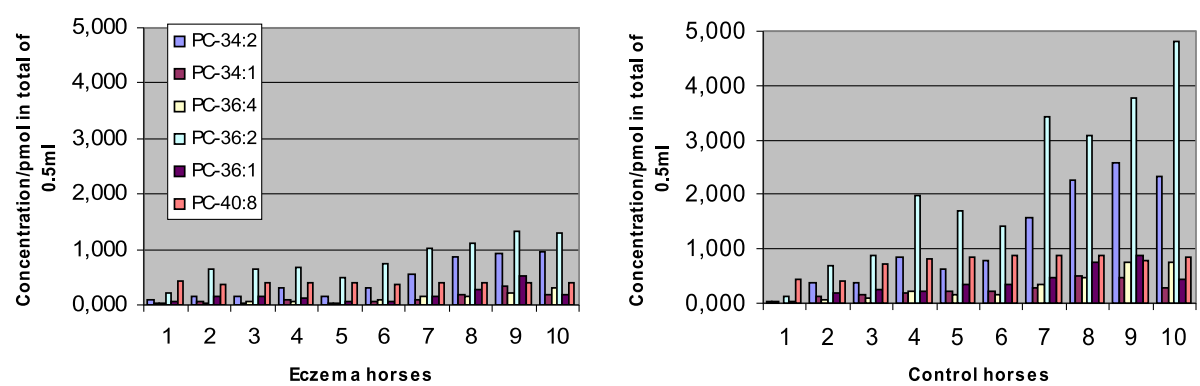

Fig. 2 Concentrations of the most abundant phosphatidylcholine (PC) species at the start of therapy. Eczema horses $(n=10)$ and their matched healthy controls $(n=10)$ are numbered similarly. All species showed significantly lower concentrations in eczema horses, at level $P<0.0001$ 

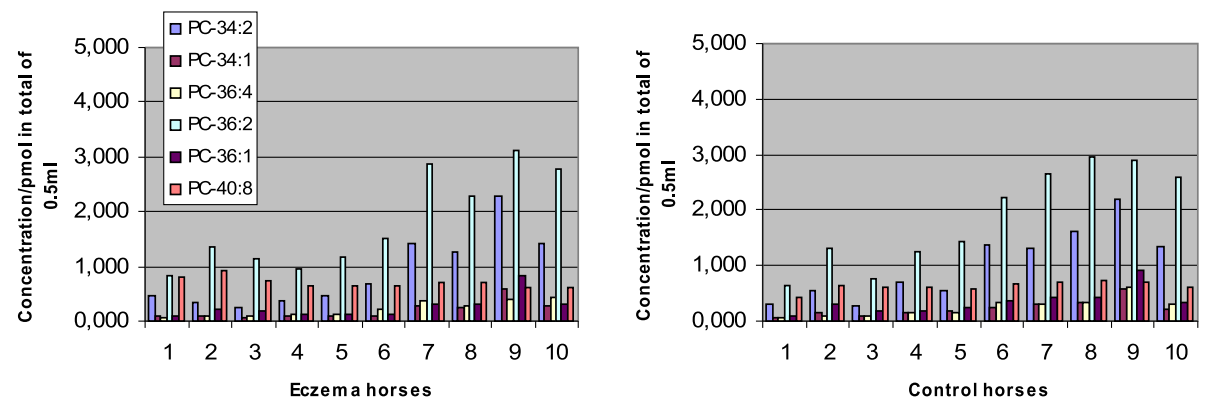

Fig. 3 Concentrations of the most abundant phosphatidylcholine (PC) species after a 4-week therapy. Eczema horses $(n=10)$ and their matched healthy controls $(n=10)$ are numbered similarly. Concentrations of PC 34:1 and 36:1 were significantly lower in eczema horses, while 40:8 was in the controls, at level $P<0.05$

our previous study [35], we found that autoserum preparations made from the sera of healthy horses and from horses with allergic eczema showed significantly different phospholipid profiles. Additionally, lipid concentrations displayed significant relationship with the severity of clinical signs. Therefore, the present study was focused on serum and changes observed in its lipid profiles in response to autoserum therapy, but not on the clinical efficacy of this therapy per se.

Horses with insect hypersensitivity showed significantly lower total concentrations of PC and SM than their matched healthy controls. After a 4-week therapy, those differences faded. The cause of these originally lower concentrations in eczema horses is unclear. Observations from earlier studies indicated that small children with elimination diets or horses fed with oil supplements show altered lipid compositions in their sera [36, 37]. In addition, fasting influences lipid concentrations [9] which stresses the relevance of matching and equal timing when blood is collected from non-fasting horses and their controls. Horses suffering from severe clinical signs may spend time for scratching and thus eat differently than healthy horses. However, none of the horses were so severely affected. Eczema horses were otherwise in a normal physical condition without signs of emaciation and their feeding regimen and daily activities were similar to their controls, neither had the owners observed any changes in their appetite. Although the feeding regimen was similar between the horses, there could be a possibility that some unknown factors might have influenced the lipid concentrations over time, since sera collected in the late summer showed more abundant concentrations of PC and SM than did sera collected earlier in the summer and this trend was detectable in both affected and healthy horses. This emphasizes the importance of matching accompanied by simultaneous samplings in these kinds of studies that are prone to environmental impacts.

Phosphatidylcholine, the major phospholipid present in mammalian sera [13, 14], was found to be the most abundant also in the present study. In humans, alterations in its concentrations have been linked to various pathological conditions, such as cancer, atopic dermatitis and type-1 diabetes, where in altered levels of both PC and SM in sera have been observed [17, 22, 23, 38]. Fuchs et al. showed that in rheumatoid arthritis, $\mathrm{PC} / \mathrm{lysoPC}$ ratio acted as an indicator of this autoimmune disease and additionally, an increased ratio seemed to be associated with the success of the therapy [39]. LysoPC is a derivative of

Table 2 Matching of the horses

\begin{tabular}{|c|c|c|c|c|c|c|c|c|c|c|}
\hline A & Breed & Gender & Age (years) & Feed & B & Breed & Gender & Age (years) & Feed & Date of $1^{\text {st }}$ sample \\
\hline 1 & Finnhorse & q & 3 & same fodder & 1 & Finnhorse & q & 9 & same fodder & 24 April \\
\hline 2 & Icelandic horse & q & 22 & same fodder & 2 & Shetland pony & q & 22 & same fodder & 21 May \\
\hline 3 & Icelandic horse & q & 23 & same fodder & 3 & Icelandic horse & $\hat{0}$ & 9 & same fodder & 21 May \\
\hline 4 & Finnhorse & $\hat{0}$ & 8 & same fodder & 4 & Finnhorse & 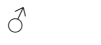 & 7 & same fodder & 12 June \\
\hline 5 & Finnhorse & $\hat{0}$ & 8 & same fodder & 5 & Finnhorse & $\hat{\sigma}$ & 7 & same fodder & 12 June \\
\hline 6 & Finnhorse & q & 8 & same pasture & 6 & Finnhorse & q & 8 & same pasture & 12 June \\
\hline 7 & Finnhorse & q & 4 & same pasture & 7 & Finnhorse & q & 7 & same pasture & 17 July \\
\hline 8 & Finnhorse & q & 4 & same pasture & 8 & Finnhorse & 우 & 6 & same pasture & 11 Aug. \\
\hline 9 & Icelandic horse & q & 10 & same fodder & 9 & Icelandic horse & q & 29 & same fodder & 7 Sept. \\
\hline 10 & Finnhorse & q & 11 & same pasture & 10 & Finnhorse & q & 19 & same pasture & 12 Sept. \\
\hline
\end{tabular}

A) 10 horses with allergic dermatitis and B) their 10 matched healthy controls. The horse and its matched control are numbered similarly 
Table 3 Pairwise comparisons of serum phospholipid concentrations

\begin{tabular}{|c|c|c|c|c|}
\hline & PC 0 & PC 4 & PCOC & PC $4 \mathrm{C}$ \\
\hline PC 0 & & $p=0.0007$ & $p<0.0001$ & $p<0.0001$ \\
\hline PC 4 & $p=0.0007$ & & ns & ns \\
\hline $\mathrm{PCOC}$ & $p<0.0001$ & ns & & ns \\
\hline \multirow[t]{2}{*}{ PC $4 \mathrm{C}$} & $p<0.0001$ & ns & ns & \\
\hline & SM 0 & SM 4 & SMOC & SM $4 \mathrm{C}$ \\
\hline SM 0 & & ns & $p=0.0115$ & ns \\
\hline SM 4 & ns & & $p=0.0005$ & ns \\
\hline SMOC & $p=0.0115$ & $p=0.0005$ & & $p=0.0186$ \\
\hline \multirow[t]{2}{*}{ SM $4 \mathrm{C}$} & ns & ns & $p=0.0186$ & \\
\hline & PI 0 & Pl 4 & $\mathrm{PIOC}$ & $\mathrm{PI} 4 \mathrm{C}$ \\
\hline PI 0 & & ns & ns & ns \\
\hline PI 4 & ns & & ns & ns \\
\hline $\mathrm{PIOC}$ & ns & ns & & ns \\
\hline \multirow[t]{2}{*}{$\mathrm{Pl} 4 \mathrm{C}$} & ns & ns & ns & \\
\hline & PE 0 & PE 4 & PE $0 \mathrm{C}$ & PE $4 \mathrm{C}$ \\
\hline PE 0 & & $p=0.0058$ & ns & $p<0.0001$ \\
\hline PE 4 & $p=0.0058$ & & ns & ns \\
\hline PE $0 \mathrm{C}$ & ns & ns & & $p=0.0018$ \\
\hline PE 4 C & $p<0.0001$ & ns & $p=0.0018$ & \\
\hline
\end{tabular}

Phosphatidylcholine (PC), sphingomyelin (SM), phosphatidylinositol (PI) and phosphatidylethanolamine (PE) detected from horses with allergic dermatitis and from their matched healthy controls (c); samples collected before (0) and 4 weeks after (4) the therapy of the affected horses

PC and it is easily formed from PC during storage at room temperature [40]. In horse sera, the relative content of lysoPC is small [14] and therefore it is not an applicable marker in horses as it is in humans. In the present study, lysoPC was detected in minor concentrations and consequently was not evaluated further. Although there was a highly significant difference in PC concentrations between the healthy and the eczema horses at the first sampling, PC did not show any correlation with the change in clinical signs, neither was there any prognostic association between the first PC concentrations and the response to therapy. In contrast to our horse study, higher levels of PC predicted better outcome in patients with atopic eczema after monoclonal antibody therapy [38].

Concentrations of SM were significantly lower in the affected than in healthy horses before the treatment, but not afterwards. Therefore, the elevated relative content of SM in eczema horses at the first sampling is in particular due to the lower levels of PC. Surprisingly, the amounts of SM decreased significantly among the control horses during the study period, which demonstrates that concentrations of certain lipids may fluctuate in healthy horses, at least to some extent without largely undermining the relative lipid content. This fluctuation possibly resulted from environmental changes, since SM concentrations decreased also in eczema horses. However, the decrease was evident only in those eczema horses that showed a poorer outcome in response to therapy. This suggests that affected horses have a specific need for SM during recovery. Sphingomyelins are important lipids involved in multiple biochemical reactions, especially in the skin and nervous tissue [15, 41-43]. These phospholipids are necessary not only as structural components, but also as bioactive regulators and messengers in cutaneous homeostasis and immune mediated responses, particularly via the main derivative, sphingosine-1phosphate $[41,42,44,45]$. Sphingosine-1-phosphate (S1P) plays a crucial part in mast cell regulation by affecting mast cell degranulation and by activating other immune cells involved [44, 45]. The engagement of S1P to its receptors on the plasma membrane seems to be the most critical point in the pathway of mast cell activation [44-46]. In addition to S1P, ceramide is another important metabolite of SM and is one of the main lipid components in skin barrier [41]. In the affected skin, ceramides are continuously utilised for repairing [41]. Although various lipid combinations and their changes
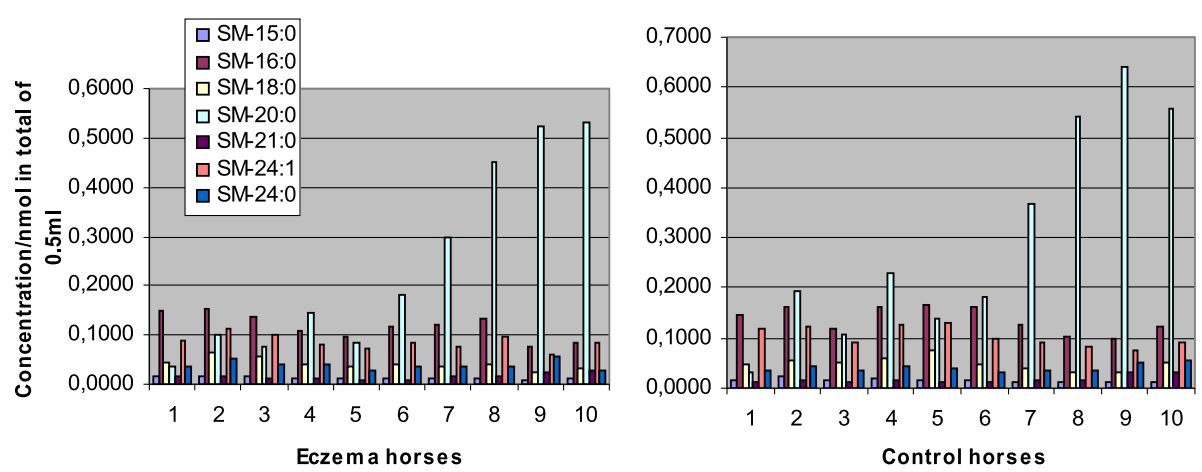

Fig. 4 Concentrations of the most abundant sphingomyelin (SM) species at the start of therapy. Eczema horses ( $n=10$ ) and their matched healthy controls $(n=10)$ are numbered similarly. Species of SM 15:0 and 24:1 showed significantly lower concentrations in eczema horses, at level $P<0.05$ 

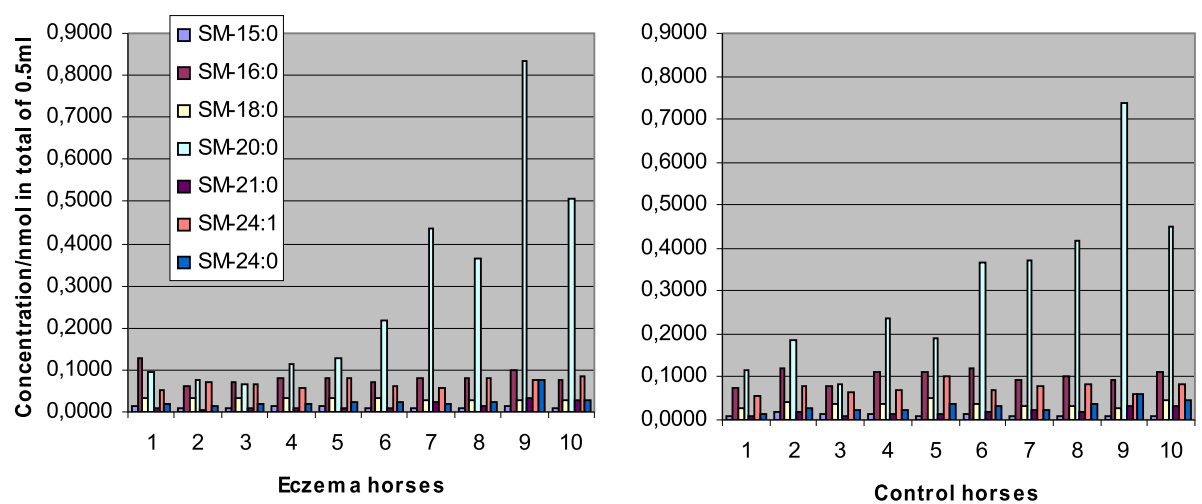

Fig. 5 Concentrations of the most abundant sphingomyelin (SM) species after a 4-week therapy. Eczema horses $(n=10)$ and their matched healthy controls $(n=10)$ are numbered similarly. Concentrations of SM 18:0 and 21:0 were significantly lower in eczema horses, at level $P<0.05$

in response to therapy have been linked to atopic dermatitis in humans [38, 47], SM seems to be a potential player in insect bite allergy of the horse, since alterations in its concentrations were significantly associated with changes in clinical signs. Similarly, sphingolipids have been shown to act as biomarkers in delayed type hypersensitivity of mice [16].

In our study, both PI and PE were detected in minor amounts, which is consistent with the previous studies [14]. These phospholipids are probably not involved in insect bite hypersensitivity, since there was no difference between the groups in the first sampling and the concentrations of PE changed similarly in both groups. Traces of PA were found in all samples and as an inner leaflet phospholipid, it is not normally detected from the horse serum [14]. Presence of PA is probably related to blood cells that remained when the samples were harvested without centrifugation [35].

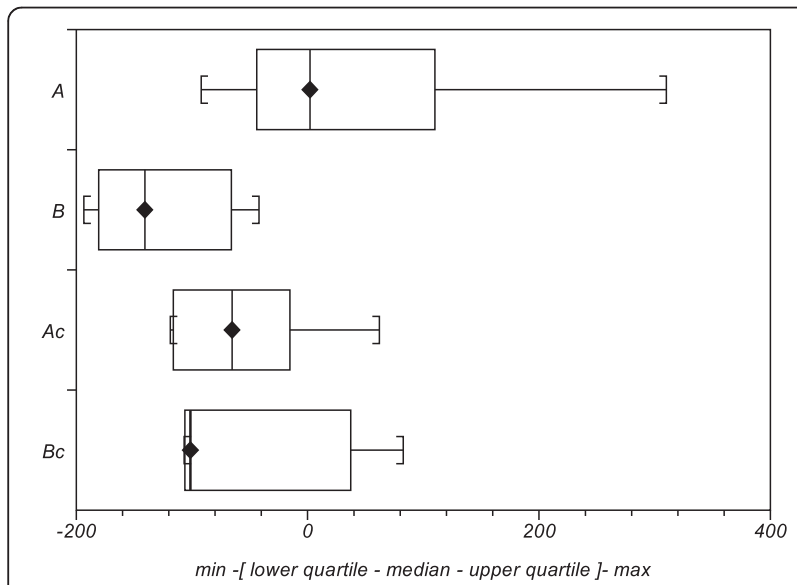

Fig. 6 Difference of sphingomyelin (SM) concentrations (pmol in total of $0.5 \mathrm{ml}$ ) after therapy. The change between the pre (stage 0-week) and the post (stage 4-week) concentrations in eczema horses with $(A, n=6)$ and without $(B, n=4)$ a positive clinical response and in their matched healthy controls (Ac and $B C$, respectively)
Horses in the present study were treated with an autoserum preparation and phospholipids were analysed in response to this treatment. However, we had no control group for the therapy; therefore it is not relevant to conclude that the observed changes could be specific for the current treatment. In fact, further studies are needed to evaluate a relationship between phospholipid concentrations and responses to therapy, comprising placebo or other therapeutic interventions and a greater number of horses than those enrolled in this study.

The lower concentration of PC and SM detected in the sera of affected horses was an unexpected finding, since our earlier study demonstrated that autoserum preparations made from the sera of horses with allergic dermatitis showed significantly higher concentrations of PC and SM than the preparations made from the sera of healthy horses [35]. This contradictory result may be associated with the hydrophobic/hydrophilic interactions of the lipid particles. The serum for autoserum preparations was collected from the superficial layer of the blood sample, washed twice with water and finally added in ethanol; all consecutive transfers were collected from the superficial layer of the previous solution [35]. Thus the most hydrophobic and water-insoluble lipid molecules were presumably concentrated in such autoserum preparations. Instead of washings, samples of the present work were mixed directly with alcohol. Therefore, these samples included not only the most hydrophobic but also the less hydrophobic lipid particles, such as PC 26:0 with a short acyl chain or PC 36:6, 38:8 and 40:8 with several double bonds; species that were not detected in autoserum preparations [35]. The discrepancy with the amounts of PC and SM in the serum versus autoserum preparations may be interpreted as so far unknown, hydrophilic/hydrophobic interactions possibly linked to mineral salts that have been found to affect peculiarly the distribution of lipids after successive washings [48]. Sera of affected horses may contain those mineral salts 
that make lipids less water-soluble and enable them to concentrate into autoserum preparations, although according to the current study the total concentrations of PC and SM were lower in these horses. This interpretation could explain with caution the underlying mechanism of this therapy, possibly culminating in the ability of signalling molecules to engage their corresponding receptors which has been recognized to be a critical event for the following mast cell responses [44-46].

\section{Conclusions}

Horses with an allergic dermatitis have an altered lipid profile in their sera as compared with healthy controls and these differences seem to change according to the clinical status of the horses. Sphingomyelin shows a functional role in equine insect bite hypersensitivity. Lipid profiling may become an important target for further studies, since relevant fingerprints delineating different pathological disorders are needed - in both human and veterinary medicine.

\section{Methods}

\section{Horses}

A total of 20 horses entered in this study in 2014, between the seasons of spring and autumn, the period when horses are exposed to bites of insects. The horses comprised 10 animals with clinical signs of insect bite hypersensitivity (eczema group) and 10 matched healthy controls (control group). The matching is presented in Table 2. Clinical signs of eczema were categorised as mild, moderate or severe at the time of blood sampling and scored 1-3, respectively. Signs were mild, if the horse had only pruritus without skin lesions. Pruritus with mild skin affections in the mane, tail (Fig. 1a) and/ or body was graded as moderate, while pruritus over large skin lesions was regarded as a severe sign. Clinical signs were evaluated after the 4-week therapy and considered as relieved when signs became milder on this scale (Fig. 1a and b). The changes in clinical signs were recorded as relieved, no change or aggravated and respectively scored as $-1,0$ or +1 . Five of the horses had mild and 5 moderate clinical signs in the beginning of the study. The matched healthy controls without a history of IBH lived in the same farms and were fed with the similar fodder as their affected counterparts. Horses were also matched with breed, gender and age as closely as possible (Table 2). The eczema horse and its matched control are numbered similarly in the tables and figures throughout this article. This study has been approved by the Regional State Administrative Agency of Southern Finland (ESAVI/1016/04.10.07/2014) and owners' signed permission for inclusion was obtained.

\section{Blood sampling}

The first sample (marked as stage 0 in text, tables and figures) was taken when the horse had shown typical clinical signs of IBH for at least 2 weeks. Blood sample was first collected using $10 \mathrm{ml}$ plain vacuum tubes that were filled in full and kept at room temperature for at least 3 hours before harvesting. The serum was harvested without using a centrifuge, thus avoiding destruction of serum lipids. With a calibrated pipette, $0.065 \mathrm{ml}$ of the serum was taken from the superficial layer and stored in $4.2 \mathrm{ml}$ of $48 \%$ ethanol. The second sample (marked as stage 4 in text, tables and figures) was collected after a 4-week therapy of the affected horse and handled equally. Samples were drawn from the counterpart horse similarly and simultaneously.

\section{Therapy of the eczema horses}

All horses in the eczema group were treated with an oral administration of an autoserum preparation for 4 weeks. Sera used for the preparations were drawn at the time of the first blood sampling. Sera were harvested without using a centrifuge and $0.065 \mathrm{ml}$ of the serum was taken from the superficial, lipid-containing layer of the tube. Lipid particles were washed twice with sterile water (1:100), accordingly $0.065 \mathrm{ml}$ collected from the superficial layer of the previous dilution. After the second washing, $0.065 \mathrm{ml}$ was taken from the superficial layer of the latter solution and added finally in $48 \%$ ethanol (1:100) and absorbed in sugar granules [49]. A dose of granules was given orally once a day for 2 weeks, followed by a 1-week pause, after which horses were medicated for one further week. Horses in the control group received no therapy.

\section{Lipid analysis of the sera}

Phospholipid classes analysed were PC, PE, PS, PI, PA and SM. All the samples stored in ethanol were subjected to Folch's method [48] for lipid extraction, dried under a $\mathrm{N}_{2}$ stream, reconstituted in $500 \mu \mathrm{l}$ chloroform/ methanol (1:2) and further spiked with the following labelled standards ${ }^{\mathrm{a}}$ corresponding to each head group: $\mathrm{D}_{9}(\mathrm{di}-44: 2)$ and $\mathrm{D}_{9}(\mathrm{di}-40: 2)$ for $\mathrm{PC}, \mathrm{D}_{4}(\mathrm{di}-40: 2)$ and $\mathrm{D}_{4}(\mathrm{di}-20: 0)$ for $\mathrm{PE}, \mathrm{D}_{3}(\mathrm{di}-40: 2)$ and $\mathrm{D}_{3}(\mathrm{di}-44: 2)$ for PS, $\mathrm{D}_{6}(\mathrm{di}-36: 2)$ and $\mathrm{D}_{6}($ di-28:0) for PI and finally unlabelled 25:0-SM. Liquid chromatography-mass spectrometry (LC-MS) with selective reaction monitoring (SRM) was used for the analyses. Waters ACQUITY Ultra Performance LC system $^{\mathrm{b}}$ equipped with a Waters ACQUITY BEH $\mathrm{C}_{18}$ column $(1.0 \times 100 \mathrm{~mm})$ was used to separate the molecular species using gradient elution. Solvent A was acetonitrile $/ \mathrm{H}_{2} \mathrm{O}(60: 40)$ with $10 \mathrm{mM}$ ammonium formate and $1 \% \mathrm{NH}_{4} \mathrm{OH}$, while solvent $\mathrm{B}$ was isopropanol/acetonitrile (90:10) containing $10 \mathrm{mM}$ ammonium formate and $1 \%$ $\mathrm{NH}_{4} \mathrm{OH}$. The flow rate was $0.13 \mathrm{ml} / \mathrm{min}$ and the column 
temperature $60{ }^{\circ} \mathrm{C}$. Solvent B was set to $40 \%$ at injection and increased linearly to $100 \%$ in $14 \mathrm{~min}$, remained at this value for $3 \mathrm{~min}$, decreased back to $40 \%$ in $1 \mathrm{~min}$ and then remained there until the end of the gradient at $20 \mathrm{~min}$. The eluent was directed to the electrospray ionization (ESI) source of Waters Quattro Premier triple-quadrupole mass spectrometer $^{\mathrm{b}}$ operated in the positive ion mode. For SRM transitions, proton adducts of the PC, PE, PS and PI species were selected as the precursors, while the product ion was either the head group (PC, SM, PI) or the diacylglycerol fragment (PE, PS). For quantification purposes, the SRM chromatograms were integrated and the relative concentrations of the individual molecular species were calculated using QuanLynx software ${ }^{\mathrm{b}}$.

Researchers processing the samples for mass spectrometric analyses were not aware of the horses' grouping. The researcher who performed clinical examinations recorded these results to another, independent researcher before the lipid analyses were made. When all studies were completed, the clinical results were combined to corresponding lipid profiles under the control of the independent supervisor.

\section{Data analysis}

The Shapiro-Wilk test was used to assess the normality of lipid concentration data. Uniformly parametric distribution was found neither in the separate phospholipids classes nor at the different stages. Therefore, pairwise comparisons of phospholipid concentrations between the matched groups and over the time were analysed by using the Friedman test. The relationship between the change of phospholipid concentrations and clinical signs was evaluated by Spearman's correlation test. Analyses were performed using statistical software StatsDirect ${ }^{\mathrm{c}}$. Two-sided P values $<0.05$ were considered significant.

\section{Competing interests}

The authors declare that they have no competing interests.

\section{Authors' contributions}

$\mathrm{RH}$ designed the study, collected the samples and wrote the main text of the manuscript. KB performed the lipid analyses and wrote this part of the text and made also additions and revisions to the final text. Both authors read and approved the final manuscript.

\section{Acknowledgements}

We thank Doc Marja Raekallio for her valuable advice, suggestions and supervision and Prof Pentti Somerharju for the cooperation with this study. We are grateful to Mrs Tarja Grundstrom and Mrs Leena Wathen for their excellent laboratory assistance. We also wish to thank the horse owners for their cooperation.

\section{Manufacturers' details}

${ }^{a}$ Avanti Polar Lipids, Alabaster, Alabama, USA; 'Waters, Milford, Massachusetts, USA; ' StatsDirect Ltd., Sale, Cheshire, UK.

\section{Author details}

${ }^{1}$ Veterinary Clinic, Nummela, Finland. ${ }^{2}$ University of Helsinki, Faculty of Veterinary Medicine, Helsinki, Finland. ${ }^{3}$ Department of Medical Biochemistry and Developmental Biology, Institute of Biomedicine, University of Helsinki, Helsinki, Finland.

Received: 25 January 2016 Accepted: 23 February 2016

Published online: 02 March 2016

\section{References}

1. Serhan CN, Petasis NA. Resolvins and protectins in inflammation-resolution. Chem Rev. 2011;111(10):5922-43. doi:10.1021/cr100396c.

2. Stables M, Gilroy D. Old and new generation lipid mediators in acute inflammation and resolution. Prog Lipid Res. 2011;50:35-51. doi:10.1016/j. plipres.2010.07.005.

3. Leslie DS, Dascher CC, Cembrola K, Townes MA, Hava DL, Hugendubler LC, Mueller E, Fox L, Roura-Mir C, Moody DB, Vincent MS, Gumperz JE, Illarionov PA, Besra GS, Reynolds CG Brenner MB. Serum lipids regulate dendritic cell CD1 expression and function. Immunology. 2008;125:289-301. doi:10.1111/j. 1365-2567.2008.02842.x.

4. Bublin $M$, Eiwegger $T$, Breiteneder $H$. Do lipids influence the allergic sensitization process? J Allergy Clin Immunol. 2014;134:521-9. doi:10.1016/j. jaci.2014.04.015.

5. Layre E, de Jong A, Moody DB. Human T cells use CD1 and MR1 to recognize lipids and small molecules. Curr Opin Chem Biol. 2014;23:31-8. doi:10.1016/j.cbpa.2014.09.007.

6. Jayawardena-Wolf J, Bendelac A. CD1 and lipid antigens: intracellular pathways for antigen presentation. Curr Opin Immunol. 2001;13:109-13.

7. De Libero G, Mori L. How immune system detects lipid antigens? Prog Lipid Res. 2009:49:120-7. doi:10.1016/j.plipres.2009.10.002.

8. van Meer G. Cellular lipidomics. EMBO J. 2005;24:3159-65.

9. Hammad SM, Pierce JS, Soodavar F, Smith KJ, Al Gadban MM, Rembiesa B, Klein RL, Hannun YA, Bielawski J, Bielawska A. Blood sphingolipidomics in healthy humans: impact of sample collection methodology. J Lipid Res. 2010;51(10):3074-87. doi:10.1194/jr.D008532.

10. Hermansson M, Uphoff A, Käkelä R, Somerharju P. Automated quantitative analysis of complex lipidomes by liquid chromatography/mass spectrometry. Anal Chem. 2005;77:2166-75.

11. Harkewicz R, Dennis EA. Applications of mass spectrometry to lipids and membranes. Annu Rev Biochem. 2011;80:301-25. doi:10.1146/annurevbiochem-060409-.

12. Shaner RL, Allegood JC, Park H, Wang E, Kelly S, Haynes CA, Sullards MC, Merrill AH Jr. Quantitative analysis of sphingolipids for lipidomics using triple quadrupole and quadrupole linear ion trap mass spectrometers. J Lipid Res. 2009;50:1692-707. doi:10.1194/jlr.D800051-JLR200.

13. Subbaiah PV, Liu M. Comparative studies on the substrate specificity of lecithin: cholesterol acyltransferase towards the molecular species of phosphatidylcholine in the plasma of 14 vertebrates. J Lipid Res. 1996;37:113-22.

14. Fuchs B, Bondzio A, Wagner U, Schiller J. Phospholipid compositions of sera and synovial fluids from dog, human and horse: a comparison by ${ }^{31} \mathrm{P}-\mathrm{NMR}$ and MALDI-TOF MS. J Animal Physiol Anim Nutr. 2009;93:410-22.

15. Quehenberger O, Dennis EA. The human plasma lipidome. N Engl J Med. 2011:365(19):1812-23. doi:10.1056/NEJMra1104901.

16. Qu F, Wu C-S, Hou J-F, Jin Y, Zhang J-L. Sphingolipids as New biomarkers for assessment of delayed-type hypersensitivity and response to triptolide. PLoS One. 2012;7:e52454. doi:10.1371/journal.pone.0052454.

17. Patel N, Vogel R, Chandra-Kuntal K, Glasgow W, Kelavkar U. A novel three serum phospholipid panel differentiates normal individuals from those with prostate cancer. PLoS One. 2014:9:1-9, e88841. doi:10.1371/journal.pone.0088841.

18. Quintana F, Yeste A, Weiner H, Covacu R. Lipids and lipid-reactive antibodies as biomarkers for multiple sclerosis. J Neuroimmunol. 2012;248: 53-7. doi:10.1016/j.jneuroim.2012.01.002.

19. Quehenberger O, Armando AM, Brown AH, Milne SB, Myers DS, Merrill AH, et al. Lipidomics reveals a remarkable diversity of lipids in human plasma. J Lipid Res. 2010;51:3299-305. doi:10.1194/jlr.M009449.

20. Fischer K, Kettunen J, Würtz P, Haller T, Havulinna AS, Kangas AJ, et al. Biomarker profiling by nuclear magnetic resonance spectroscopy for the prediction of all-cause mortality: an observational study of 17,345 persons. PLoS Med. 2014;11(2):e1001606. doi:10.1371/journal.pmed.1001606.

21. González-Dominguez R, Garcia-Barrera T, Gómez-Ariza JL. Metabolomic study of lipids in serum for biomarker discovery in Alzheimer's disease using 
direct infusion mass spectrometry. J Pharmaceut Biomed. 2014;98:321-6. doi:10.1016/jpba.2014.05.023

22. Oresic M, Gopalacharyulu P, Mykkänen J, Lietzen N, Mäkinen M, Nygren H, et al. Cord serum lipidome in prediction of islet autoimmunity and type 1 diabetes. Diabetes. 2013;62:3268-74. doi:10.2337/db13-0159.

23. Ried JS, Baurecht H, Stückler F, Krumsiek J, Gieger C, Heinrich J, et al. Integrative genetic and metabolite profiling analysis suggests altered phosphatidylcholine metabolism in asthma. Allergy. 2013;68:629-36. doi:10.1111/all.12110

24. Scott DW, Miller Jr WH. Insect hypersensitivity. In: Kersey R, LeMelledo D, editors. Equine dermatology. St. Louis: Saunders, Elsevier Science; 2003. p. 458-74.

25. Heimann M, Janda J, Sigurdardottir OG, Svansson V, Klukowska J, von Tscharner C, Doherr M, Broström H, Andersson LS, Einarsson S, Marti E, Torsteinsdottir S. Skin-infiltrating T cells and cytokine expression in Icelandic horses affected with insect bite hypersensitivity: a possible role for regulatory T cells. Vet Immunol Immunopathol. 2011;140:63-74.

26. Schaffartzik A, Hamza E, Janda J, Crameri R, Marti E, Rhyner C. Equine insect bite hypersensitivity: what do we know? Vet Immunol Immunopathol. 2012;147:113-26.

27. Jose-Cunilleras E, Kohn CW, Hillier A, Saville WJA, Lorch G. Intradermal testing in healthy horses and horses with chronic obstructive pulmonary disease, recurrent urticaria, or allergic dermatitis. JAVMA. 2001;219:1115-21.

28. Kurotaki T, Narayama K, Oyamada T, Yoshikawa H, Yoshikawa T. Immunopathological study on equine insect hypersensitivity ("kasen") in Japan. J Comp Pathol. 1994;110:145-52.

29. Wagner B, Miller WH, Morgan EE, Hillegas JM, Erb HN, Leibold W, Antczak DF. IgE and lgG antibodies in skin allergy of the horse. Vet Res. 2006;37:813-25.

30. Novak N, Leung DYM. Advances in atopic dermatitis. Curr Opin Immunol. 2011;23:778-83. doi:10.1016/j.coi.2011.09.007.

31. Dubrac S, Schmuth M, Ebner S. Atopic dermatitis: the role of Langerhans cells in disease pathogenesis. Immunol Cell Biol. 2010;88:400-9. doi:10.1038/icb.2010.33.

32. Kawakami T, Ando T, Kimura M, Wilson BS, Kawakami Y. Mast cells in atopic dermatitis. Curr Opin Immunol. 2009;21:666-78. doi:10.1016/j.coi.2009.09.006.

33. Olsén L, Bondesson U, Broström H, Olsson U, Mazogi B, Sundqvist M, Tjälve $H$, Ingvast-Larsson C. Pharmacokinetics and effects of cetirizine in horses with insect bite hypersensitivity. The Vet J. 2011;187:347-51. doi:10.1016/.tvjl.2009.12.030.

34. Ginel PJ, Hernandez E, Lucena R, Blanco B, Novales M, Mozos E. Allergenspecific immunotherapy in horses with insect bite hypersensitivity: a double-blind, randomized, placebo-controlled study. Vet Dermatol. 2014:25:29-e10. doi:10.1111/vde.12092.

35. Hallamaa RE, Batchu KC, Tallberg T. Phospholipids in sera of horses with summer eczema: lipid analysis of the autoserum preparation used in therapy. Equine Vet J. 2014;46:322-7. doi:10.1111/evj.12135.

36. Paassilta M, Kuusela E, Korppi M, Lemponen R, Kaila M, Nikkari ST. Food allergy in small children carries a risk of essential fatty acid deficiency, as detected by elevated serum mead acid proportion of total fatty acids. Lipids Health Dis. 2014;13:180. doi:10.1186/1476-511X-13-180.

37. O'Connor $\mathrm{Cl}$, Lawrence LM, Hayes SH. Dietary fish oil supplementation affects serum fatty acid concentrations in horses. J Anim Sci. 2007:85:2183-9.

38. Hotze M, Baurecth H, Rodriguez E, Chapman-Rothe N, Ollert M, Fölster-Holst $\mathrm{R}$, et al. Increased efficacy of omalizumab in atopic dermatitis patients with wild-type filaggrin status and higher serum levels of phosphatidylcholines. Allergy. 2014;69:132-5. doi:10.1111/all.12234.

39. Fuchs B, Schiller J, Wagner U, Häntzschel H, Arnold K. The phosphatidylcholine/ lysophosphatidylcholine ratio in human plasma is an indicator of the severity of rheumatoid arthritis: Investigations by ${ }^{31}$ P NMR and MALDI-TOF MS. Clin Biochem. 2005;38:925-33. doi:10.1016/j.clinbiochem.2005.06.006.

40. Breier M, Wahl S, Prehn C, Fugmann M, Ferrari U, Weise M, et al. Targeted metabolomics identifies reliable and stable metabolites in human serum and plasma samples. PLoS One. 2014;9:1-11;e89728. doi:10.1371/journal. pone.0089728.

41. Proksch E, Jensen J-M, Elias PM. Skin lipids and epidermal differentiation in atopic dermatitis. Clin Dermatol. 2003;21:134-44.

42. Kendall A, Nicolaou A. Bioactive lipid mediators in skin inflammation and immunity. Prog Lipid Res. 2013;52:141-64. doi:10.1016/j.plipres.2012.10.003.

43. Vesper H, Schmelz E-M, Nikolova-Karakashian MN, Dillehay DL, Lynch DV, Merrill Jr AH. Sphingolipids in food and the emerging importance of sphingolipids to nutrition. J Nutr. 1999;129:1239-50.
44. Olivera A, Rivera J. Sphingolipids and the balancing of immune cell function: lessons from the mast cell. J Immunol. 2005;174:1153-8. doi:10.4049/jimmunol.174.3.1153.

45. Price MM, Oskeritzian CA, Milstien S, Spiegel S. Sphingosine-1-phosphate synthesis and functions in mast cells. Future Lipidol. 2008;3:665-74. doi:10.2217/17460875.3.6.665.

46. Kulinski JM, Munoz-Cano R, Olivera A. Sphingosine-1-phosphate and other lipid mediators generated by mast cells as critical players in allergy and mast cell function. Eur J Pharmacol. 2015; doi:10.1016/j.ejphar.2015.02.058.

47. Laitinen K, Sallinen J, Linderborg K, Isolauri E. Serum, cheek cell and breast milk fatty acid compositions in infants with atopic and non-atopic eczema. Clin Exp Allergy. 2006;36:166-73.

48. Folch J, Lees M, Sloane Stanley GH. A simple method for the isolation and purification of total lipides from animal tissues. J Biol Chem. 1957;226(1):497-509.

49. Hallamaa RE. Autoserum preparation in the treatment of equine summer eczema: Findings over 12 years. Equine Vet Educ. 2010;22:610-5. doi:10.1111/j.2042-3292.2010.00143.x.

\section{Submit your next manuscript to BioMed Central and we will help you at every step:}

- We accept pre-submission inquiries

- Our selector tool helps you to find the most relevant journal

- We provide round the clock customer support

- Convenient online submission

- Thorough peer review

- Inclusion in PubMed and all major indexing services

- Maximum visibility for your research

Submit your manuscript at www.biomedcentral.com/submit

( BioMed Central 